\title{
A SIMPLE, IMPROVED AND SOLVENT FREE TRANSAMIDATION USING GLYCINE
}

\author{
Medikonda Manorajani ${ }^{1, *}$ and Tatavarti Bhagya Kumar ${ }^{2}$ \\ ${ }^{1}$ Department of Chemistry, Post Graduate Centre, P.B. Sidharatha Arts \& Science College, \\ Vijayawada, Andhra Pradesh. India. Pin-520010 \\ ${ }^{2}$ Department of Chemistry, KBN College, Vijayawada, Andhra Pradesh. India. Pin-520010 \\ *E-mail: drmanoranjani@yahoo.com
}

\begin{abstract}
We here in the report a rapid and expeditious transamidation of various amides that include phthalimide also with aliphatic primary and secondary and aromatic amines to produce the respective amides using glycine as a catalyst. The reaction was carried out with $10 \mathrm{~mol} \%$ glycine, which is cheap and abundant. All the compounds could give the respective products in good to excellent yields. In addition to the operational simplicity, the present methodology has the advantages such as it is solvent free and excess amine used for the transamidation could be easily recovered. Keywords: Transamidation, Glycine, Condensation, Solvent Free, Green Chemistry.
\end{abstract}

@ RASĀYAN. All rights reserved

\section{INTRODUCTION}

Transamidation is an attractive tool in synthetic organic chemistry in which the amine part of the amide is replaced by another amine i.e. exchange of amines in amides. Owing to the stability of the carboxamides, the synthetic chemists have the least appreciation for the transamidation as it requires harsh conditions that would limit the substrate scope, expansive metal catalysts. ${ }^{1}$ However, it is an important reaction for the simple reason that the amide functionality is often used as protecting group for carboxylic acid functionality and it is very frequent in the context of peptide chemistry (Scheme-1). Therefore, to be able to extend the peptide chain or similar from such a protection, it requires the deprotection and then coupling of the amino acid using the stoichiometric amount of the coupling reagent. But, notably, the transamidation has reduced the number of steps such as deprotection and coupling with a coupling reagent and it could be achieved within one step. Having mentioned the advantage of the transamidation, it is significant to improve such a methodology so to achieve the transformation under relatively milder conditions, with cheap and abundant catalysts.

In this connection, there have been many reports that describe the synthesis of amides using the transamidation methodology. In the last two decades, Stahl, ${ }^{3}$ Williams, ${ }^{4}$ Myers, ${ }^{5}$ Beller, ${ }^{6}$ and other groups have contributed significant methods ${ }^{7}$. Despite the advances achieved, each of these methods suffers from the use of transition metal or lanthanide metal catalysts to promote this transformation efficiently. Xu and co-workers have developed methodology for transamidation using the benzoic acid in which they could demonstrate a wide substrate scope and better yields. ${ }^{8}$ The thorough examination of the mechanism from this report, interestingly it had revealed that the fact that, it is all about the activation of the carbonyl group of the amide for which an acid or a Lewis acid was necessary. Therefore, we want to take the simple, cheap and abundant acids and try whether it would furnish the desired product under relatively milder conditions.

\section{General Remarks}

All reagents were purchased from commercial sources and used without any further purification unless mentioned otherwise. Melting points were uncorrected. Thin-layer chromatograms were run on glass plates coated with silica gel G for TLC, using the solvent system EtOAc/hexane. 
Compounds were purified by column chromatography using silica gel (60-120 mesh) with EtOAc/hexane (of specific proportion as required) as an eluent. ${ }^{1} \mathrm{H}$ NMR (400 and $600 \mathrm{MHz}$ ) and ${ }^{13} \mathrm{C}$ NMR (100 and 150 $\mathrm{MHz}$ ) were recorded using $\mathrm{CDCl}_{3}$ as a solvent. Chemical shifts $(\delta)$ are reported in parts per million (ppm), internal reference $(0.05 \%$ to $1 \%)$ tetramethylsilane. Coupling constants $(\mathrm{J})$ are reported in $\mathrm{Hz}$ : singlet (s), doublet (d), triplet (t), a doublet of doublet (dd), multiple (m), or broad (br). IR spectra were recorded on IR spectrometer; Data for previously reported compounds (cited/cited therein) matched well with our observed data. All the starting materials i.e. amides have been prepared using the literature reports and each of it is several reported with DCC/DMAP method. The isolated yields are almost quantitative every time the characterization is followed by purification with recrystallization and is by matching the melting point with the reported ones.

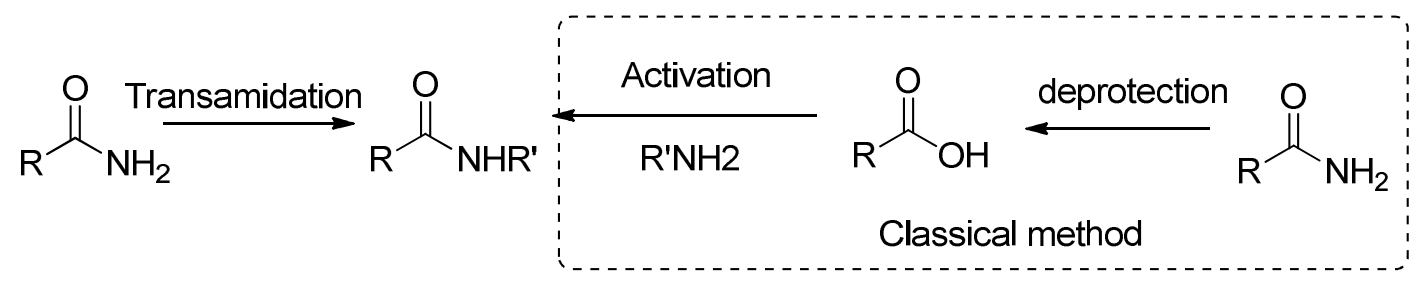

Scheme-1: Transamidation

\section{A typical procedure for the Transamidation using Glycine}

The representative procedure for the synthesis of N-phenyl benzamide is as follows. A mixture of amide $(1 \mathrm{mmol})$, amine $(5 \mathrm{mmol})$ and glycine $(10 \mathrm{~mol} \%)$ was stirred in round bottom flask at $80{ }^{\circ} \mathrm{C}$ temperature for $24 \mathrm{~h}$. After being cooled to room temperature, $20 \mathrm{~mL}$ of water was added and extracted with DCM $(3 \times 20 \mathrm{~mL})$. After removal of solvent, the crude reaction mixture left out was purified by silica gel (200400mesh) column chromatography (dissolved in dichloromethane, eluted with dichloromethane and ethyl acetate) followed by recrystallization

(1) N-benzylbenzamide (entry 1, 4, 5 Table 1) ${ }^{7}$ : Eluent: 40\% EtOAc in Hexane; White solid; 94\% yield (0.198 g); ${ }^{1} \mathrm{H}$ NMR (400 MHz, $\left.\mathrm{CDCl}_{3}\right) \delta$ 7.79-7.58 (m, 2H),7.52-7.25 (m, 8H), 6.67 (br s, 1H, NH), 4.62 $(\mathrm{d}, \mathrm{J}=14.5 \mathrm{~Hz}, 2 \mathrm{H}){ }^{13} \mathrm{C} \mathrm{NMR}\left(100 \mathrm{MHz}, \mathrm{CDCl}_{3}\right) \delta 167.4,138.2,134.3,131.5,128.7,128.5,127.8$, 127.5, 127.0, 44.0.

(2) N-benzyl-4-nitrobenzamide (entry 2, Table 1) ${ }^{7:}$ Eluent: $40 \%$ EtOAc in Hexane; colorless solid $96 \%$ $(0.245 \mathrm{~g},) .{ }^{1} \mathrm{H}$ NMR $\left(400 \mathrm{MHz}, \mathrm{CDCl}_{3}\right) \delta 8.22(\mathrm{~d}, J=8.8 \mathrm{~Hz}, 2 \mathrm{H}), 7.92(\mathrm{~d}, J=8.8 \mathrm{~Hz}, 2 \mathrm{H}), 7.37-7.27$ $(\mathrm{m}, 5 \mathrm{H}), 6.75(\mathrm{~s}, 1 \mathrm{H}), 4.62(\mathrm{~d}, J=5.7 \mathrm{~Hz}, 2 \mathrm{H}) .{ }^{13} \mathrm{C} \mathrm{NMR}\left(100 \mathrm{MHz}, \mathrm{CDCl}_{3}\right) \delta 168.06,152.17,142.51$, $140.07,131.56,130.88,130.58,126.46,47.06$.

(3) N-benzyl-4-methylbenzamide (entry 3. Table 1) ${ }^{\mathbf{8}}$ : Eluent: $30 \%$ EtOAc in Hexane; colorless solid $81 \%(0.182 \mathrm{~g},) .{ }^{1} \mathrm{H}$ NMR $\left(400 \mathrm{MHz}, \mathrm{CDCl}_{3}\right) \delta 7.72-7.66(\mathrm{~m}, 2 \mathrm{H}), 7.38-7.26(\mathrm{~m}, 5 \mathrm{H}), 6.40(\mathrm{bs}, 2 \mathrm{H})$, $4.64(\mathrm{~d}, \quad \mathrm{~J}=5.65 \mathrm{~Hz}, 2 \mathrm{H}), 2.39(\mathrm{~s}, 3 \mathrm{H}) .{ }^{13} \mathrm{C} \mathrm{NMR}\left(100 \mathrm{MHz}, \mathrm{CDCl}_{3}\right) \quad 167.47,141.93,138.50$, $131.58,129.23,128.74,127.88,127.50,127.10,44.02,21.49$.

(4) N-phenylbenzamide (entry 6, Table 1) ${ }^{7}$ : Eluent: 50\% EtOAc in Hexane; off white solid $78 \%(0.153$ g, ) ${ }^{1} \mathrm{H}$ NMR $\left(300 \mathrm{MHz}, \mathrm{CDCl}_{3}\right): \delta=7.09(1 \mathrm{H}, \mathrm{t}, J=7.5 \mathrm{~Hz}, \mathrm{Ph}), 7.30(2 \mathrm{H}, \mathrm{t}, J=7.5 \mathrm{~Hz}, \mathrm{Ph}), 7.40-7.49$ $(3 \mathrm{H}, \mathrm{m}, \mathrm{Ph}), 7.58(2 \mathrm{H}, \mathrm{d}, J=7.5 \mathrm{~Hz}, \mathrm{Ph}), 7.74(1 \mathrm{H}, \mathrm{brs}, \mathrm{NH}), 7.80(2 \mathrm{H}, \mathrm{d}, J=6.9 \mathrm{~Hz}, \mathrm{Ph}) ;{ }^{13} \mathrm{C}$ NMR $(75$ $\left.\mathrm{MHz}, \mathrm{CDCl}_{3}\right): \delta=120.2,124.6,127.0,128.8,129.1,131.9,135.1,137.9,165.7$.

(5) cyclohexyl(phenyl)methanone (entry 7, 8, 9 Table 1) ${ }^{8}$ : Eluent: 60\% EtOAc in Hexane; White solid; yield (for 7, $91 \%$ (0.172 g), for 8, 96\% (0.181 g) and for 9, 85\% $0.160 \mathrm{~g})$ ); ${ }^{1} \mathrm{H} \mathrm{NMR}\left(400 \mathrm{MHz}, \mathrm{CDCl}_{3}\right) \delta$ 
7.77-7.72 (m, 2H), 7.49-7.37 (m,3H), 6.01 (brs, $1 \mathrm{H}, \mathrm{NH}), 4.00-3.96(\mathrm{~m}, 1 \mathrm{H}), 2.06-1.15(\mathrm{~m}, 10 \mathrm{H}) .{ }^{13} \mathrm{C}$ NMR (100 MHz, $\left.\mathrm{CDCl}_{3}\right) \delta 166.6,135.1,131.2,128.5,126.8,48.6,33.2,25.5,24.9$.

(6) N-benzyl-2-phenylacetamide (entry 10, Table 1) ${ }^{9}$ : Eluent: 50\% EtOAc in Hexane; white solid, yield

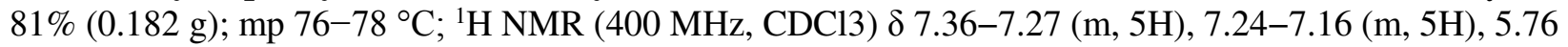
(br, 1H), $4.42(\mathrm{~s}, 2 \mathrm{H}), 3.62(\mathrm{~s}, 2 \mathrm{H}) ;{ }^{13} \mathrm{C} \mathrm{NMR}\left(100 \mathrm{MHz}, \mathrm{CDCl}_{3}\right) \delta 171.1,138.3,135.0,129.4,129.0$, 128.7, 127.5, 127.4, 127.3, 43.7, 43.6.

(7) N-benzyl-2-(4-nitrophenyl)acetamide (entry 11, Table 1) ${ }^{7}$ : Eluent: $40 \%$ EtOAc in Hexane; yellow solid; Yield $83 \%(, 0.224 \mathrm{~g}){ }^{1} \mathrm{H}$ NMR $\left(400 \mathrm{MHz}, \mathrm{CDCl}_{3}\right) \delta 8.22(\mathrm{~d}, J=8.8 \mathrm{~Hz}, 2 \mathrm{H}), 7.92(\mathrm{~d}, J=8.8 \mathrm{~Hz}$, 2H), $7.37-7.27(\mathrm{~m}, 5 \mathrm{H}), 6.75(\mathrm{~s}, 1 \mathrm{H}), 4.62(\mathrm{~d}, J=5.7 \mathrm{~Hz}, 2 \mathrm{H}) .{ }^{13} \mathrm{C}$ NMR $(100 \mathrm{MHz}, \mathrm{CDC} 13) \delta 167$. $6,155.6,143.3,140.07,130.8,130.2,130.1,126.4,47.9$.

(8) 2-benzylisoindoline-1,3-dione (entry 12, Table 1) ${ }^{7}$ : Eluent: 40\% EtOAc in Hexane ; Yield 39\% (, $0.092 \mathrm{~g})$; colorless solid ${ }^{1} \mathrm{H}$ NMR $\left(400 \mathrm{MHz}, \mathrm{CDCl}_{3}\right) \delta 7.87(\mathrm{~d}, J=5.3 \mathrm{~Hz}, 2 \mathrm{H}), 7.71-7.62(\mathrm{~m}, 2 \mathrm{H}), 7.40$ $(\mathrm{d}, J=7.8 \mathrm{~Hz}, 2 \mathrm{H}), 7.36(\mathrm{t}, J=7.4 \mathrm{~Hz}, 2 \mathrm{H}), 7.20(\mathrm{t}, J=7.3 \mathrm{~Hz}, 1 \mathrm{H}), 4.81(\mathrm{~s}, 2 \mathrm{H}) .{ }^{13} \mathrm{C}$ NMR $(100 \mathrm{MHz}$, $\left.\mathrm{CDCl}_{3}\right) \delta 171.2,139.3,135.8,132.1,131.7,130.6,125.9,44.7$.

\section{RESULTS AND DISCUSSION}

We started our studies on transamidation of $N$-phenyl benzamide with benzylamine as a model system along with various organic acids that include acetic acid, 4-nitrobenzoic acid, glycine, and para toluene sulfonic acid at $80-100{ }^{\circ} \mathrm{C}$. Out of all these acids, glycine as a catalyst at $80{ }^{\circ} \mathrm{C}$ worked better in terms of yield, the time is taken for the completion of the reaction and temperature at which the reaction was carried. Gratifyingly, with glycine, the reaction took place in $4 \mathrm{~h}$ and furnished the desired product in excellent yield $94 \%$. However, the excessive usage of benzylamine was necessary to preclude the solvent. In order to make the present methodology meet the Green chemistry principles, we have recovered all the excessive $\mathrm{BnNH}_{2}$ along with the stoichiometric amount of aniline from the work up. To prove the catalytic effect of Glycine, we have performed the same reaction in the absence of catalyst as well. But there was no progress (from TLC) noticed even after $24 \mathrm{~h}$ heating at the specified temperature and hence, the reaction was aborted. Further to evaluate the loading of catalyst, we have screened various amounts of glycine i.e $5 \mathrm{~mol} \%, 10 \mathrm{~mol} \%, 15 \mathrm{~mol} \%$ and $20 \mathrm{~mol} \%$. But the best results in terms of yield were obtained when $10 \mathrm{~mol} \%$ was used as it can be seen from Table-1 using the test reaction.

Table-1: Optimization of the catalyst quantity

\begin{tabular}{c|c|c}
\hline Entry No & Acid & Isolated yield of the product (\%) \\
\hline 1 & Acetic acid $(100 \mathrm{~mol} \%)$ & 28 \\
\hline 2 & 4-nitrobenzoic acid $(100 \mathrm{~mol} \%)$ & 36 \\
\hline 3 & p-Toluene sulfonic acid & 43 \\
\hline 4 & $0 \mathrm{~mol} \%$ & $\mathrm{ND}$ \\
\hline 5 & $5 \mathrm{~mol} \%$ & 76 \\
\hline 6 & $10 \mathrm{~mol} \%$ & 94 \\
\hline 7 & $15 \mathrm{~mol} \%$ & 92 \\
\hline 8 & $20 \mathrm{~mol} \%$ & 89 \\
\hline
\end{tabular}

${ }^{i}$ solated product weight after the purification

With the optimized conditions in hand, we went on to expand the substrate scope under the conditions specified above. The detailed study of the electrometric effects has been studied as the results were depicted in Table-2. Initially, the acid part has been substituted with various groups that alter the electron density (entry 1,2, and 3, Table-2). As it was already mentioned, when N-phenyl benzamide is subjected to the reaction conditions, the yield observed was $94 \%$, but when the acid part of the amide is substituted 
RASĀYAN J. Chem.

Vol. 10 | No. 4 |1305-1310 | October - December | 2017

with an electron withdrawing group at the para position i.e. $\mathrm{N}$-phenyl 4-nitro benzamide, the isolated yield of the desired product was slightly more than its counterpart.

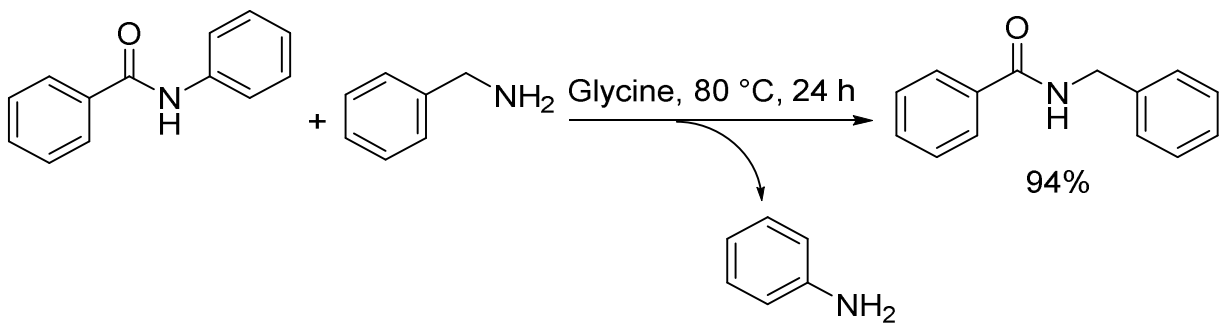

Table-2: The synthesis of $N$-Benzyl benzamides

\begin{tabular}{|c|c|c|c|}
\hline Entry & Amide & Amine & Yield $(\%)^{b}$ \\
\hline 1 & & & 94 \\
\hline 2 & & & 96 \\
\hline 3 & & & 81 \\
\hline 4 & & & 88 \\
\hline 5 & & & 91 \\
\hline 6 & & & 78 \\
\hline 7 & & & 91 \\
\hline 8 & & & 96 \\
\hline 0 & & & \\
\hline 10 & & & 81 \\
\hline 11 & & & 83 \\
\hline 12 & & & 39 \\
\hline
\end{tabular}

A Reaction condition: N-Phenyl benzamide (1 mmol), benzylamine $(5 \mathrm{mmol})$, Glycine $(10 \mathrm{~mol} \%)$ at $80^{\circ} \mathrm{C}$ for $24 \mathrm{~h}$. ${ }^{\text {b}}$ Yield was determined by ${ }^{1} \mathrm{H}$ NMR analysis. 
Whereas the same with opposite effect i.e. electron donating group was placed then yield of the desired product was slightly dropped down. Having seen this effect, it can be attributed to the fact that the carbocation nature of the amide carbon is the key to the formation the product in various amounts. That is when an electron withdrawing group is present, the electrons from the benzene ring are least available through the resonance. The carbonyl carbon of the amide and hence the attack of the amine at this specific position is feasible to result in the better yield. In contrast to this, when an electron donating group is placed, the opposite effect is noticed.

Similarly, the same effect was found be true and in agreement with the literature as well, when this electrometric effect has been studied with the amine part of the amide as well (entry 3, 4 and 5, Table-1). That is, when amine of the amide is substituted with an electron withdrawing group i.e. nitro at the $4^{\text {th }}$ position results in the better yield of the desired product (91\%) than its counterpart (88\%) i.e. when substituted with a long alkyl group. Therefore, this effect is concrete and general. Furthermore, the transamidation with less nucleophilic aniline is also investigated. When N-phenyl benzamide was subjected with the aniline under the optimized condition, did not give the desired product which could be reasoned for the same nucleophilicity of the aniline (Not shown in the table). But, when $N$ - 4-nitrophenyl benzamide was subjected to the reaction, there was progress and subsequently, $78 \%$ of the product was isolated by the column chromatography (entry 6, Table-1).

The reaction with the secondary amine i.e. piperidine is quite faster $(<3 \mathrm{~h})$ and yielded better in comparison with the primary amine (entry 5 and 8), i.e. when $N$ - 4-nitrophenyl benzamide is subjected to the reaction conditions with the piperidine $(5 \mathrm{mmol})$ the yield isolated was $96 \%$ whereas with benzylamines it was $91 \%$. It is noteworthy, that the preparation of secondary amides using the transamidation method has been reported to be sluggish and often required harsh conditions. ${ }^{1 \mathrm{~b}}$ Interestingly, in the present methodology being reported, it does not require any special condition of such. Furthermore, the reaction was quite faster and as it was mentioned even the yield was better.

The present methodology is equally sensitive to the nucleophilic nature of the amines as well and it was found to be better for the sterically less hindered secondary amines than the corresponding primary amines. The amides of aliphatic acids such as phenylacetic acid and 4-nitro phenylacetic acid underwent the reaction and furnished the product in good yield as well. But in case of phthalimide (entry 12), the reaction was not very spurring (35\%) and the subsequent study of this will be reported in due course of time

\section{CONCLUSION}

The summary of the present work is that we have developed a newer methodology for the transamidation in which the amine part of the amide is replaced by the new amine of choice. The present methodology has been significantly important for the following reasons 1) The catalyst used was glycine which is cheap and abundant, 2) The present methodology is green process as it is free from the solvent and excessive used amine has been recovered each time almost quantitative amount after column chromatography along with the expelled amine, 3) The detailed study of the electromeric effect has been studied which can again be summarized as follows. a) The present methodology yields lower yields when an electron donating group at an appropriate group is present at an appropriate position of either amine part of the amide or acid part of the amide, b) replacement of the primary amine with secondary amines is better than the primary amines.

Therefore, its utility is unabated. The yields obtained are excellent to very good. However, it has a shortcoming with phthalimide which is being investigated with improved conditions which will be communicated in the due course of time. Hence, this methodology, presumably, will find application in the context of natural product synthesis.

\section{ACKNOWLEDGEMENT}

The authors sincerely thank the management of KBN College and P. B. Siddhartha Arts and Science College, Vijayawada for the generous support to carry out the research project. 


\section{REFERENCES}

1. (a.)A. C. Liana, N. Benjamin, Atkinson, M. J. W. Jonathan, Angew. Chem. Int. Ed., 51, (2012); (b) L. B. Emma, M. Y. Michael, Y. Zhou, M. A. Sarah, K. G. Neil , Nature Commun., 7, 11554 (2016); (c) V. R. Pattabiraman, J. W. Bode, Nature, 480, 471 (2011).

2. (a) N. A. Stephenson, J. Zhu, S. H. Gellman, S. S. Stahl, J. Am. Chem. Soc., 131, 10003 (2009). (b) J. M. Hoerter, K. M. Otte, S. H. Gellman, Q. Cui , S. S. Stahl J. Am. Chem. Soc., 130,647 (2008). (c) D. A. Kissounko, J. M. Hoerter, L. A. Guzei, Q. Cui, S. H. Gellman, S. S. Stahl, J. Am. Chem. Soc., 129, 1776 (2007). (d) J. M. Hoerter, K. M. Otte, S. H.Gellman, S. S. Stahl , J. Am. Chem. Soc., 128, 5177 (2006) (e) D. A. Kissounko, L. A. Guzei, S. H. Gellman, S. S. Stahl Organometallics, 24, 5208 (2005). (f) S. E. Eldred, D. A. Stone, S. H. Gellman, S. S. Stahl, J. Am. Chem. Soc., 125, 3422 (2003).

3. B.N. Atkinson, A. R. Chhatwal, H. V. Lomax, J. W. Walton, J. M. J. Williams, Chem. Commun., 48, 11626 (2012).

4. T. A. Dineen, M. A. Zajac, A. G. Myers. J. Am. Chem. Soc., 128, 16406 (2006).

5. M. Zhang, S. Imm, S. Bahn, L. Neubert, H. Neumann, M. Beller, Angew. Chem., Int. Ed., 51, 3905 (2012).

6. S. R. Nageswara, D. M. Chandra, S. Adimurthy, Org. Lett., 15, 1496 (2013)

7. W. Ji-Wei, W. Ya-Dong, D. Jian-Jun, X. Hua-Jian, Adv. Synth. Catal., 51, 1383(2016).

8. T. Fredrik, V. Oscar, P. J. G. Karl, T. Cheuk-Wai, B. Jan-E, A. Hans, Chem. Eur. J., 20, 5885 (2014).

9. D. Dharm, B. P. Nani, T. Kishore, C Jyoti, M. Bhubaneswar, J. Org. Chem., 79, 5420 (2014)

[RJC-1637/2017] 